Kalpa Publications in Engineering
Volume 1, 2017, Pages 287-293
$\begin{aligned} & \text { ICRISET2017. International Conference on Re- } \\ & \text { search and Innovations in Science, Engineering } \\ & \text { \&Technology. Selected Papers in Engineering }\end{aligned}$

\title{
Computational Analysis of Ultrasonic Treatment of Melt for Effective Dispersion of Reinforcement Particles
}

\author{
Vivek S Ayar ${ }^{1}$, Hardik K Parmar ${ }^{2}$, Mayur P Sutaria ${ }^{3}$ \\ ${ }^{1,3}$ Department of Mechanical Enginnering, C.S.P.I.T.,CHARUSAT, Changa \\ ${ }^{2}$ Department of Mechanical Engineering, S.P.C.E., Bakrol \\ vivekahir17@yahoo.com, hardikparmar61@gmail.com, \\ mayursutaria@gmail.com
}

\begin{abstract}
In many engineering fluids, micro or nano solid particles are introduced to enhance their effect. Introduction of nanoparticles in radiator coolant enhance its efficiency and introduction of micro/nano reinforcement particles in liquid metals enhance its mechanical properties. In most of the applications, de-agglomeration of particle clusters and uniform dispersion of particles is desirable to enhance the process. Ultrasonic streaming and cavitation can help in achieving the desirable output. In this work, the ultrasonic streaming and dispersion of micro $\mathrm{SiC}$ particles in water and liquid Aluminium were numerically simulated (using COMSOL multiphysics) and compared. Parameters selected for carrying out the investigations were power of ultrasonic generator and diameter (tip) of probe. Results obtained for water were validated by experimental results. The medium viscosity and density are the key factors influencing ultrasonic streaming and cavitation. The results provide reference for the ultrasonic treatment of melts for making Metal Matrix Composites (MMCs).

Keywords- Ultrasonic stirring, Cavitation, MMCs, Ultrasonic Power, Acoustic pressure, Probe tip diameter
\end{abstract}

\section{Introduction}

With the advancement of the technology, demand for materials with light weight, high strength, and having good tribological properties is ever increasing. Industries in automobile, aerospace, defense and other sector are in constant need for material with good strength, toughness even at the elevated temperature, where conventional materials fail to provide a combination of all the required properties. Thus, to fulfil the demand from the emerging trends, composite materials were developed. Particles of high strength are added in ductile metal to make metal matrix composites having 
intermediate properties. The matrix is usually an alloy, and the reinforcements are usually a ceramic. Metal matrix composite combines metallic properties of matrix alloys with ceramic properties of reinforcements, resulted in better strength [1]. Silicon Carbide (SiC) are mostly used as a reinforcement particles in aluminium matrix composites. Other widely used reinforcements are aluminium oxide $\left(\mathrm{Al}_{2} \mathrm{O}_{3}\right)$, Boron Carbide $\left(\mathrm{B}_{4} \mathrm{C}\right)$, Aluminium Nitride (AlN). Due to attenuation in the system's free energy, agglomeration occurred for making MMCs [2].

Due to the attraction forces in between the particles, large as well as small clusters are formed. To break those clusters, stirring becomes necessary. Mechanical stirring doesn't provide required power to break the smaller clusters [3]. Numerical simulations of acoustic waves in the melt had been done by Huang et al. [4] using COMSOL multiphysics software. The Power of generator was $1000 \mathrm{~W}$. To analyse the acoustic pressure in the melt, two separate model was applied by them. To simulate the acoustic wave in medium, acoustic power was converted to a pressure source boundary as $P_{\mathrm{S}}=\mathrm{P}_{\mathrm{A}}[\cos (\omega t)]$, where $\mathrm{P}_{\mathrm{A}}=\left(2 \rho c W / \pi R^{2}\right)^{1 / 2}, W$ is the power of ultrasonic generator and $R$ is the tip radius of the probe. Kang et al.[5] performed numerical simulation (using Fluent), to study ultrasonic streaming and cavitation in water, liquid aluminium and liquid steel. The power of ultrasonic generator was kept $200 \mathrm{~W}$. Zhang et al.[6] investigated the distribution of $\mathrm{SiC}$ nanoparticles in liquid aluminium with the help of Ansys's Fluent DDPM (Dense Discrete phase model). The position of injecting the particles were different. In order to predict the particle trajectories, they have accounted several forces acting on a particle. They concluded that the final distribution of nanoparticles is independent of injection positions. Jia et al.[7] used CFD model which accounts for turbulent fluid flow, heat transfer, and the complex interaction between the molten alloy and nanoparticles. Ultrasonic generator of $1750 \mathrm{~W}$ and frequency of $18000 \mathrm{~Hz}$ was used to perform ultrasonic treatment. The fluid flow characteristics for uniform distribution of the nanoparticles into the 6061 matrix was numerically investigated by Zhang et al.[8]. The multiphase CFD model using the Ansys's Fluent Dense Discrete Phase Model (DDPM) and a particle engulfment and pushing (PEP) model, the dispersion of $\mathrm{SiC}$ nanoparticles with different injection positions, fluid flow, and locations of probe have been investigated. The frequency was set as $18000 \mathrm{~Hz}$. Wang et al.[9] studied the effect of temperature range on ultrasonic treatment of primary $\mathrm{Al}_{3} \mathrm{Ti}$. They used power of the system as 4000 $\mathrm{W}$ and a frequency of $17500 \mathrm{~Hz}$. Ultrasonic treatment of melt with high intensity was applied to an Al-0.4 wt $\%$ Ti alloy. The selected temperature ranges kept in three set : above liquidus (810 to $\left.770^{\circ} \mathrm{C}\right)$, across liquidus $\left(770\right.$ to $\left.730{ }^{\circ} \mathrm{C}\right)$, and below liquidus $\left(730\right.$ to $\left.690^{\circ} \mathrm{C}\right)$.

Metal matrix composite made by stir casting are affected by various material and process parameters like stirring speed, viscosity, blade design, crucible design, clearance from bottom of crucible to stirrer blade, pouring temperature, size of reinforcement, stirring time [1]. Clustering of particles occur on the upper side of melt in conventional stir casting method. It was observed that few particles remain at bottom of the crucible after mechanically stirring and did not mix properly in the melt. To overcome this issues, Researchers introduced ultrasonic vibrations in the slurries. Before conducting experiment, it is must to know which parameters play important role in Ultrasonic treatment of slurries. Such parameters are tip-diameter of probe, power of generator, frequency etc[11]. It is found that many of researchers have performed the ultrasonic treatment to liquid metals for making metal matrix composites, few of them have gone through the simulation work. The range of power and tip diameter observed in the literature are $1000 \mathrm{~W}$ to $4000 \mathrm{~W}$ and $20 \mathrm{~mm}$ to $40 \mathrm{~mm}$, respectively with frequency of $20000 \mathrm{~Hz}$.

The objective of present work is to investigate the effect of ultrasonic process parameters on cavitation region and particle trajectories in liquid medium. Initially, numerical simulation of ultrasonic treatment was carried out in the water using COMSOL multiphysics software, and subsequently experimental validation has been carried out. Later, the numerical simulation of liquid aluminium melt has been carried out at different power and probe tip diameter. 


\section{Computational Analysis}

Present work includes analysis of the four cases for as listed in Table 1. Two different size of probe having $6 \mathrm{~mm}$ and $25 \mathrm{~mm}$ tip diameter were used. The mediums considered for numerical simulation analysis were water \& liquid aluminium (melt). In all cases $\mathrm{SiC}$ particles of average size 44 micron were added $5 \%$ by weight of medium.

COMSOL software was used to simulate the acoustic wave in water \&liquid aluminium (melt) by using Frequency based Pressure Acoustic Module and Particle Tracing for Fluid Flow Module [12]. The probe of $6 \mathrm{~mm}$ and $25 \mathrm{~mm}$ tip diameter were submerged $20 \mathrm{~mm}$ vertically in to the metal pool in container. The height of liquid pool was $80 \mathrm{~mm}$ and diameter of $75 \mathrm{~mm}$ (300 $\mathrm{ml}$ of water). The ultrasound with power of $300 \mathrm{~W}$ and $1500 \mathrm{~W}$ having frequency $20000 \mathrm{~Hz}$ was introduced into the liquid pool along the gravity direction.

Table 1. Cases taken for simulation work

\begin{tabular}{|c|c|c|c|}
\hline Case no. & Power (W) & Tip dia (mm) & Medium \\
\hline 1 & 300 & 6 & Water \\
\hline 2 & 300 & 6 & Liquid Aluminium \\
\hline 2 & 300 & 25 & Liquid Aluminium \\
\hline 4 & 1500 & 25 & Liquid Aluminium \\
\hline
\end{tabular}

The acoustic power was converted to a pressure source boundary as $P_{\mathrm{s}}$ where $R$ is end face radius of the probe.

$$
P_{S}=\sqrt{\frac{2 * \rho * c * W}{\pi R^{2}}} \cos (\omega t)
$$

A very important parameter of the ultrasonic field one that determines to a great extent the efficiency of processing is the ultrasonic intensity $I$. Intensity of sound is measured in Watts per square meter $\left(\mathrm{W} / \mathrm{m}^{2}\right)$ is given by $I$ where $W$ is power and $S$ is area of probe tip.

$$
I=\frac{W}{S}
$$

Amplitude A is given by,

$$
A=\frac{1}{2 \pi f} \sqrt{\frac{2 I}{\rho c}}
$$

Table 2 shows the parameter used to analyze the ultrasonic intensity, pressure, acceleration and amplitude of the system. The speed of sound in liquid aluminium is taken as $4600 \mathrm{~m} / \mathrm{s}$ [11].

Table 2. Parameters and values

\begin{tabular}{|l|c|c|}
\hline Parameter & Sign & value \\
\hline Power & $\mathrm{W}$ & $300,1500 \mathrm{~W}$ \\
\hline Frequency & $\mathrm{f}$ & $20000 \mathrm{~Hz}$ \\
\hline Density of Al. (L) & $\rho_{\mathrm{Al}}$ & $2350 \mathrm{~kg} / \mathrm{m}^{3}$ \\
\hline Density of Water & $\rho_{\mathrm{w}}$ & $1000 \mathrm{~kg} / \mathrm{m}^{3}$ \\
\hline Dia. of probe & $\mathrm{d}$ & $6,25 \mathrm{~mm}$ \\
\hline Speed of sound in Al.(L) & $\mathrm{c}_{\mathrm{Al}}$ & $4600 \mathrm{~m} / \mathrm{s}$ \\
\hline Speed of sound in Water & $\mathrm{c}_{\mathrm{w}}$ & $1500 \mathrm{~m} / \mathrm{s}$ \\
\hline Viscosity of Al.(L) & $\mathrm{v}_{\mathrm{Al}}$ & $0.0027 \mathrm{~Pa} . \mathrm{s}$ \\
\hline Impedance of Glass & $\mathrm{Z}_{\mathrm{glass}}$ & $10.92 \mathrm{MPa} . \mathrm{s} / \mathrm{m}^{2}$ \\
\hline Impedance of Crucible (Graphite) & $\mathrm{Z}$ & $12.4 \mathrm{MPa} . \mathrm{s} / \mathrm{m}^{2}$ \\
\hline
\end{tabular}


With the help of these parameters, ultrasonic intensity, acoustic pressure and the amplitude was analytically calculated which are listed in Table 3 . It shows case-wise variation in ultrasound intensity, pressure and amplitude.

Table 3.Analytical values of acoustic parameter for liquid aluminium

\begin{tabular}{|c|c|c|c|}
\hline Case no. & $\begin{array}{c}\text { Ultrasonic } \\
\text { Intensity } \\
\left(\mathbf{W} / \mathbf{m}^{\mathbf{2}}\right)\end{array}$ & $\begin{array}{c}\text { Pressure } \\
(\mathbf{M P a})\end{array}$ & $\begin{array}{c}\text { Amplitude } \\
(\boldsymbol{\mu m})\end{array}$ \\
\hline 1 & 10615711 & 5.64 & 29.9 \\
\hline 2 & 10615711 & 15.15 & 11.158 \\
\hline 3 & 611465 & 3.64 & 2.67 \\
\hline 4 & 3057325 & 8.13 & 5.98 \\
\hline
\end{tabular}

\section{Results and Validation}

Analysis results give pressure distribution, velocity of fluid flow and the trajectories of particles in mediums. The velocity and pressure obtained in fluid flow for all cases are listed in Table 4.

Table 4. Simulation results

\begin{tabular}{|c|c|c|c|}
\hline \multirow{2}{*}{ Case no. } & \multicolumn{2}{|c|}{ Velocity Obtained of Fluid flow $(\mathrm{m} / \mathrm{s})$} & \multirow{2}{*}{$\begin{array}{c}\text { Pressure } \\
\text { (MPa) }\end{array}$} \\
\hline & Max & Min & \\
\hline 1 & 17.6 & 0.23 & 5.86 \\
\hline 2 & 19.7 & 0.2 & 15.2 \\
\hline 3 & 2.74 & 0.12 & 3.64 \\
\hline 4 & 6.12 & 0.26 & 8.13 \\
\hline
\end{tabular}

\section{A. Water medium (Case 1)}

Fig 1 shows the acoustic pressure produced in water at $300 \mathrm{~W}$ and tip diameter of $6 \mathrm{~mm}$. Cavitation threshold pressure for water is $0.1034 \mathrm{MPa}$ [5], and cavitation is observed in more than $50 \%$ of medium. As the acoustic waves generate in the medium, it caused the suspended particles to disperse. Fig 2 shows the particle trajectories in the water medium after $1 \mathrm{sec}$. Using the similar parameters setting, physical experiment has been carried out (Fig 3). It clearly reveals close matching of particle dispersion after $1 \mathrm{sec}$.

\section{B. Liquid Aluminium medium (Case 2,3 \& 4)}

Fig 4 and 5 show the acoustic pressure produced in liquid aluminium using $300 \mathrm{~W}$ and tip diameter of $6 \mathrm{~mm}$ and $25 \mathrm{~mm}$ respectively. The attenuation in pressure was observed as it reaches to the bottom of the container. Based on the cavitation threshold value of $1 \mathrm{MPa}$ for pure liquid aluminium [3], cavitation zone could cover most of the melt volume in case 3 (Fig 5), indicating that the tip diameter of $25 \mathrm{~mm}$ give better results than $6 \mathrm{~mm}$ for same power and medium. Fig 6,7 and 8 show the velocity contours for case 2, 3 and 4 for fluid flow. As observed in pressure distribution, acoustic flow achieves maximum value under the tip of probe and tends to give circulation effect. It decreased significantly as reaching the bottom of the container. It is observed in Fig 6 and 7 that as the tip diameter increases (with same power), the velocity of fluid flow is significantly decreases from $19.7 \mathrm{~m} / \mathrm{s}$ to $2.74 \mathrm{~m} / \mathrm{s}$. As the power increases (with same probe tip diameter), velocity of fluid flow increased from $2.74 \mathrm{~m} / \mathrm{s}$ to $6.12 \mathrm{~m} / \mathrm{s}$. Fig 9 and 10 show the particle trajectories for case 3 and 4 at $1 \mathrm{sec}$. It clearly indicates that the low intensity power is not able to give proper distribution of the particles. 


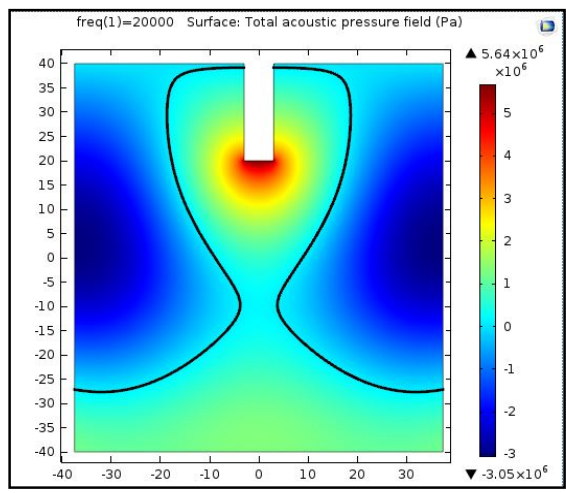

Fig 1. Acoustic pressure in water at $300 \mathrm{~W}$ and $6 \mathrm{~mm}$ tip dia (Case 1)

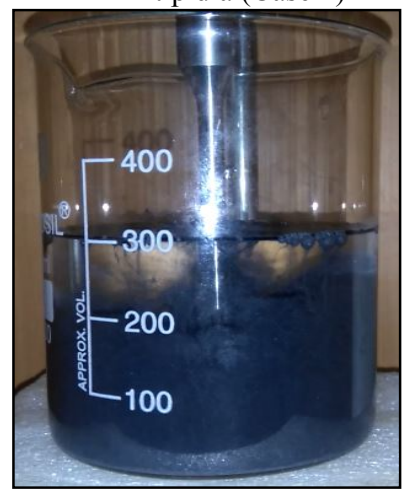

Fig 3. Experiment result

Particle trajectories in water at $1 \mathrm{sec}$

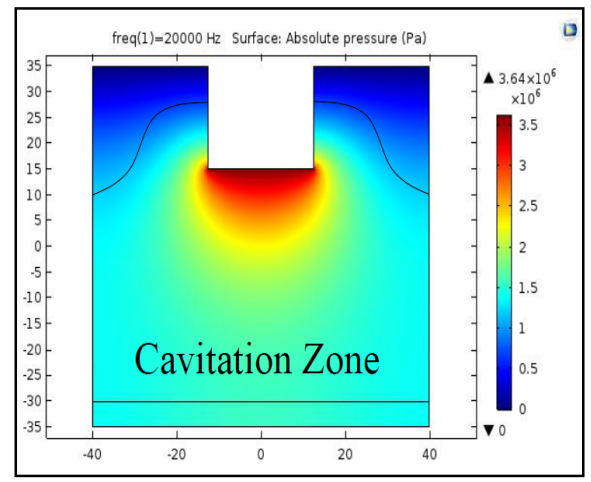

Fig 5. Acoustic pressure in liquid aluminium at $300 \mathrm{~W}$ and $25 \mathrm{~mm}$ tip dia (Case 3)

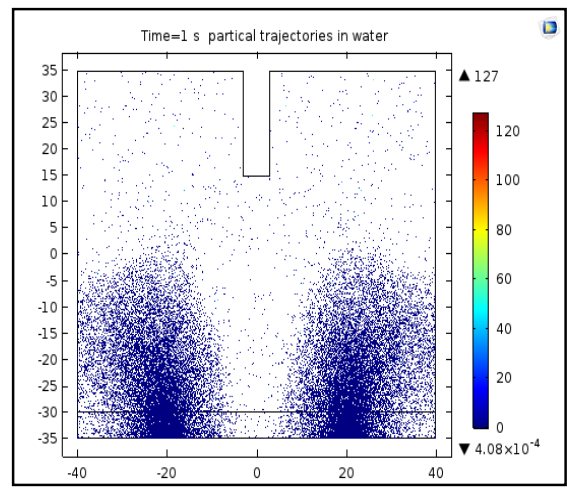

Fig 2 Simulation Result Particle trajectories in water at $1 \mathrm{sec}$

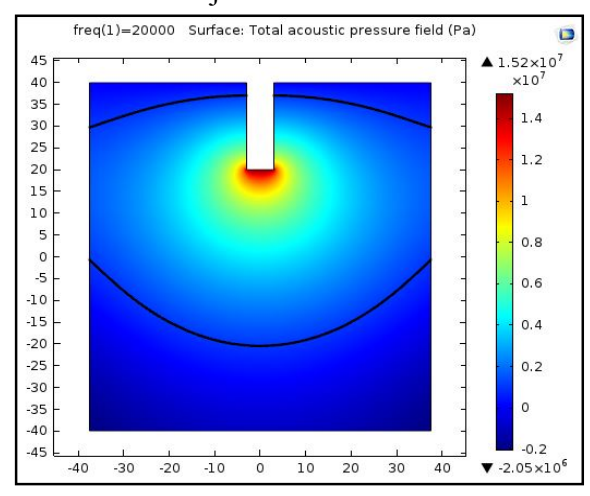

Fig 4. Acoustic pressure in liquid aluminium at $300 \mathrm{~W}$ and $6 \mathrm{~mm}$ tip dia (Case 2)

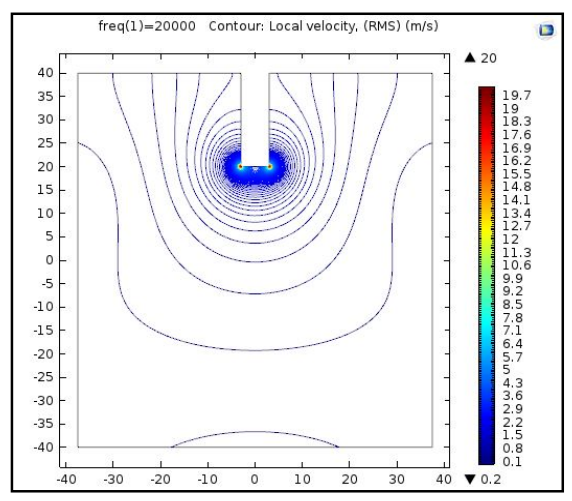

Fig 6. Velocity contour of Case 2 


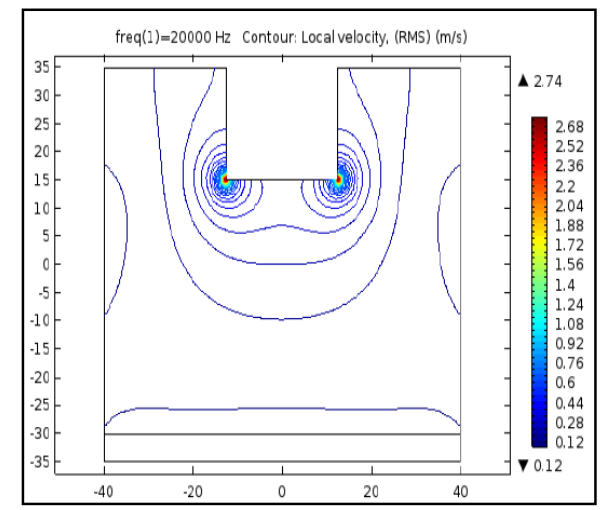

Fig 7. Velocity contour of Case 3

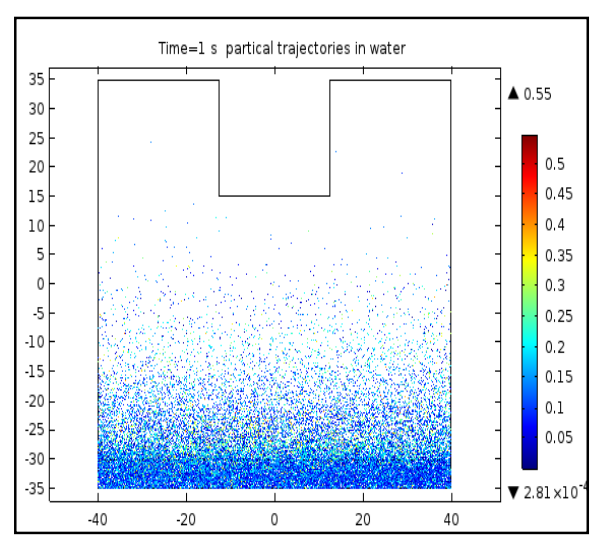

Fig 9. Particle trajectories in Case 3 at $1 \mathrm{sec}$

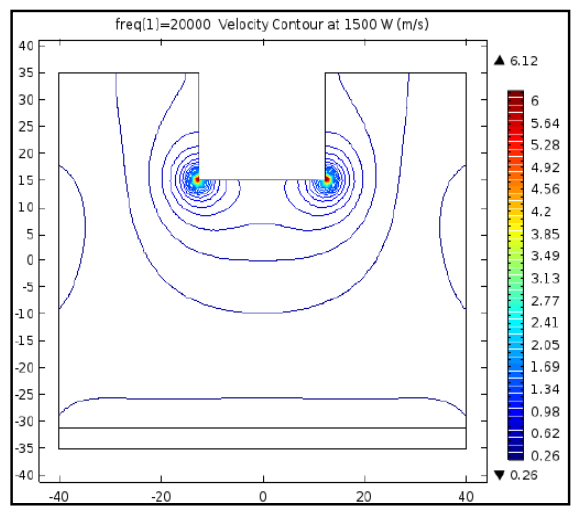

Fig 8. Velocity contour of Case 4

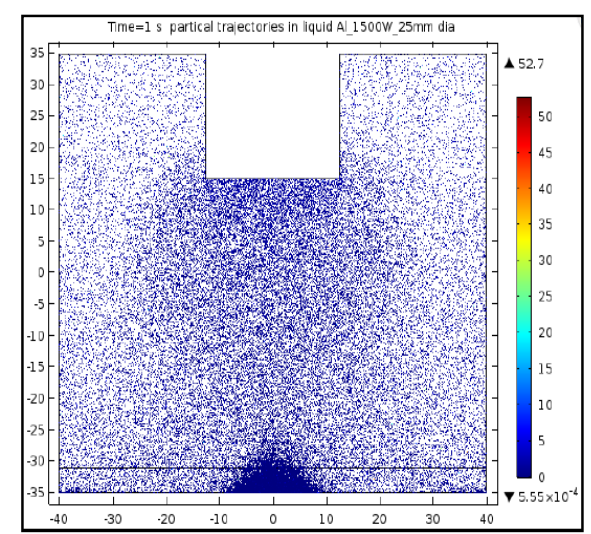

Fig 10. Particle trajectories in Case 4, (a) at 1 sec.

\section{Conclusion}

Total four cases were analysed and the summary of conclusions is presented in Table 5. Numerical simulation assists in visualization of cavitation zone and the particle trajectories, leading to the better understanding of the process. As the tip diameter increased (with same power), the maximum velocity of fluid flow was decreased $86 \%$ and as the power increased (with same probe tip diameter), the maximum velocity of fluid flow was increased $220 \%$. In case 3 (Fig 5) effective cavitation was observed in medium, but low intensity power $(300 \mathrm{~W})$ does not create the required intensity to distribute particles in the medium (Fig 9). In liquid aluminium melt using $1500 \mathrm{~W}$ power and $25 \mathrm{~mm}$ probe tip diameter resulted in uniform distribution of particles with effective cavitation (Fig 10).

Table 5. Conclusion table

\begin{tabular}{|c|c|c|c|c|c|}
\hline \multirow{2}{*}{$\begin{array}{c}\text { Case } \\
\text { no. }\end{array}$} & \multirow{2}{*}{$\begin{array}{c}\text { Power } \\
(\mathbf{W})\end{array}$} & \multirow{2}{*}{$\begin{array}{c}\text { Tip dia } \\
(\mathbf{m m})\end{array}$} & Medium & Cavitation & $\begin{array}{c}\text { Particle } \\
\text { Distribution }\end{array}$ \\
\hline 1 & 300 & 6 & Water & Yes & Yes \\
\hline 2 & 300 & 6 & Liq. $\mathrm{Al}$ & No & -- \\
\hline 3 & 300 & 25 & Liq. $\mathrm{Al}$ & Yes & No \\
\hline 4 & 1500 & 25 & Liq. $\mathrm{Al}$ & Yes & Yes \\
\hline
\end{tabular}




\section{Acknowledgements}

We express our cavernous thanks to CHARUSAT university and Department of Science and Technology (Ref No. DST/TSG/AMT/2015/332) for supporting the project work. We would also like to thank Dr. Rucha Desai, who helped in carrying the research work.

\section{References}

[01] Surappa M. K., "Aluminium matrix composites: Challenges and opportunities," vol. 28, 2003, pp. 319-334.

[02] Liu Z., Han Q., Li J., and Huang W., "Journal of Materials Processing Technology Effect of ultrasonic vibration on microstructural evolution of the reinforcements and degassing of in situ TiB 2p / Al - 12Si - 4Cu composites," J. Mater. Process. Tech., vol. 212, no. 2, 2012, pp. 365371.

[03] Hashim J., Looney L., and Hashmi M. S. J., "Particle distribution in cast metal matrix composites-Part II," J. Mater. Process. Technol., vol. 123, no. 2, 2002, pp. 258-263.

[04] Huang H. J., Xu Y. F., Shu D., Han Y. F., Wang J., and Sun B. De, "Effect of ultrasonic melt treatment on structure refinement of solidified high purity aluminium," Trans. Nonferrous Met. Soc. China (English Ed., vol. 24, no. 7, 2014, pp. 2414-2419.

[05] Kang J., Zhang X., Wang S., Ma J., and Huang T., "The comparison of ultrasonic effects in different metal melts," Ultrasonics, vol. 57, 2015 pp. 11-17.

[06] Zhang D. and Nastac L., "Numerical modeling of the dispersion of ceramic nanoparticles during ultrasonic processing of aluminium-based nanocomposites ," Integr. Med. Res., vol. 3, no. 4,2014, pp. 296-302.

[07] Jia S., Zhang D., and Nastac L., "Experimental and Numerical Analysis of the 6061-Based Nanocomposites Fabricated via Ultrasonic Processing," no. Ref 20, 2015, pp. 2-10.

[08] Zhang X., Kang J., Wang S., Ma J., and Huang T., "The effect of ultrasonic processing on solidification microstructure and heat transfer in stainless steel melt," Ultrason. Sonochem., vol. 27, 2015 pp. 307-315.

[09] Wang F., Eskin D., Connolley T., and Mi J., "Effect of ultrasonic melt treatment on the refinement of primary A13Ti intermetallic in an Al-0.4Ti alloy," J. Cryst. Growth, vol. 435, 2016, pp. 24-30.

[10] Kang J., Zhang X., Hu Y., Ma J., Hu Y., and Huang T., "Ultrasonic Treatment of the 304 Stainless Steel Melt," vol. 54, no. 2, 2014, pp. 281-287.

[11] Eskin G. I., "Principles of Ultrasonic Treatment : Application for Light Alloys Melts," vol. 232, 1997, pp. 223-232.

[12] COMSOL3 "Introduction to the Particle Tracing Module." COMSOL Multiphysics, 2016. 